\title{
Habitat selection models for European wildcat conservation
}

\author{
Nina Klar ${ }^{\mathrm{a}, \mathrm{b}, *}$, Néstor Fernández ${ }^{\mathrm{c}, \mathrm{a}}$, Stephanie Kramer-Schadt ${ }^{\mathrm{a}, \mathrm{d}}$, Mathias Herrmann ${ }^{\mathrm{e}}$, \\ Manfred Trinzen ${ }^{\mathrm{f}}$, Ingrid Büttner ${ }^{\mathrm{f}}$, Carsten Niemitz ${ }^{\mathrm{b}}$ \\ ${ }^{a}$ Department of Ecological Modelling, Helmholtz Centre for Environmental Research - UFZ, Permoser Straße 15, D-04318 Leipzig, Germany \\ ${ }^{\mathrm{b}}$ Department of Human Biology and Anthropology, Freie Universität Berlin, Albrecht-Thaer-Weg 6, 14195 Berlin, Germany \\ ${ }^{\mathrm{c}}$ Department of Ecology and Plant Biology, University of Almería, Ctra. Sacramento s/n La Cañada de San Urbano, 04120 Almería, Spain \\ ${ }^{\mathrm{d} D e p a r t m e n t ~ o f ~ B i o l o g y, ~ U n i v e r s i t y ~ o f ~ B e r g e n, ~ T h o r m ø h l e n s g a t e ~ 55, ~ N-5200 ~ B e r g e n, ~ N o r w a y ~}$ \\ eOEKO-LOG.COM, Hof 30, 16247 Parlow, Germany \\ ${ }^{\mathrm{f}}$ Biologische Station im Kreis Euskirchen e.V., Steinfelder Straße 10, 53947 Nettersheim, Germany
}

Keywords:

Carnivore conservation

Felis silvestris

Use-availability habitat model

Germany

GLMM

European habitats directive

\section{A B S T R A C T}

Populations of the European wildcat (Felis silvestris) are only slowly recovering in Central Europe after a severe decline in the last centuries and require specific conservation plans in many areas. However, detailed information on wildcat occurrence and habitat requirements is still scarce and controversial. We present a fine-scale habitat selection model for wildcats based on detailed species and land use information and evaluate its accuracy to predict habitat distribution in new areas. We analysed habitat use within home ranges using single locations of 12 radio-tracked individuals from south western Germany. Several competing models were fitted and compared using generalised linear mixed models (GLMM) and information-theoretic approaches. Radio-tracking data of 9 and 10 wildcats from two distant areas were used to evaluate the models. The selected model predicted habitat associated to close distance to forest, watercourses and meadows and a critical distance to villages, single houses and roads. To predict area suitable for home ranges we superimposed rules derived from home range attributes at a higher level of selection. Predictions from the combination of the fine-scale habitat model and home range rules matched well with more than 2000 wildcat observations of southwestern Germany. We discuss the application of the model in wildcat conservation for finding potential reintroduction sites, identifying small isolated populations and aiding in the evaluation of the needs of mitigation and compensation within the scope of the European Habitats Directive.

\section{Introduction}

Where does a species occur and where could it occur are the two initial questions in wildlife conservation planning (Peterson and Dunham, 2003). In recent years, the development of predictive habitat models has greatly improved our ability to address both questions. First, models can help to detect the occurrence of cryptic or rare species difficult to survey (e.g. Pearce et al., 2001; Fernández et al., 2006a). Second, mapping habitat predictions can further be used to assess the impact

\footnotetext{
* Corresponding author: Address: Department of Ecological Modelling, Helmholtz Centre for Environmental Research - UFZ, Permoser Street 15, D-04318 Leipzig, Germany. Tel.: +49 4023818082.

E-mail addresses: ninaklar@gmx.de (N. Klar), nestor@ual.es (N. Fernández), Stephanie.Kramer@ufz.de (S. Kramer-Schadt), oeko-log@ t-online.de (M. Herrmann), mtrinzen@t-online.de (M. Trinzen), ingridbuettner@t-online.de (I. Buttner), cniemitz@zedat.fu-berlin.de (C. Niemitz).
} 
of changing land use, to detect important areas for reintroduction, and to identify potential conflicts with human activities (e.g. Johnson et al., 2004; Kramer-Schadt et al., 2005; Sawyer et al., 2006).

Habitat models based on presence-absence data are the most standard approach to habitat modelling (e.g. Schadt et al., 2002b; Woolf et al., 2002; Naves et al., 2003; Seoane et al., 2003; Niedzialkowska et al., 2006). These models are often based on coarse-grained landscape and species information allowing coarse habitat inferences and predictions, but they may overlook biological details important for species conservation. Indeed, fine-scale models based on detailed species and landscape information have shown a great potential to detect crucial habitat structures not obvious at broader scales (e.g. Fernández et al., 2003). However, the expandability of fine-scale models for habitat predictions remains largely unexplored partly because the required information is difficult to gather. Therefore, one current challenge in conservation is to reconcile fine-scale habitat inferences with broadscale predictions required for more comprehensive species management. This approach has great potential in the design of mitigation and compensation measures required within the European habitats directive for species under protection.

A typical example for a cryptic species difficult to detect and listed in the European habitats directive in appendix IV is the European wildcat (Felis silvestris, Schreber, 1777). Once widely distributed throughout Europe, this medium-sized carnivore has suffered significant reduction in its original range due to extensive hunting and trapping resulting in fragmented and small populations (Piechocki, 1990). Wildcats were for a long time seen as a serious competitor for hunters, despite its specialisation on small mammals, especially rodents, in Central Europe (Sládek, 1973; Stahl, 1986; Kozená, 1990; Liberek, 1999; Biró et al., 2005). During the last decades, wildcats have slowly recovered in Central Europe, due to total protection and reduced trapping (Stubbe and Stubbe, 2002; Pott-Dörfer and Raimer, 2004). However, habitat degradation, direct kills and hybridisation with feral cats (Felis S. catus) are still important threats for many populations (Stahl and Artois, 1995; Pierpaoli et al., 2003; Lecis et al., 2006). In addition, their large home ranges and their high mobility make this species highly vulnerable to traffic mortality, especially in densely populated landscapes. Therefore, potential impact on this species has to be assessed and compensatory measures as well as reintroductions should be considered where necessary.

The inconspicuous behaviour of wildcats, the easy confusion with its domesticated relative, the feral cat, low population densities and the fact that there is nearly no risk of becoming a threat to domestic livestock contributed to quasi-ignorance of the species (Stahl and Artois, 1995). Hence, detailed information on occurrence and potential occurrence as well as on wildcat habitat requirements is still scarce and controversial (Stahl and Artois, 1995; Lozano et al., 2003).

The present study aims to develop fine-scale habitat selection models for wildcats using detailed species and habitat information and to evaluate their reliability to predict habitats over a broad spatial extent. For this, we first designed a set of models and compared their fit using radio-tracking data and fine-grained landscape information from one wildcat population in western Germany. Then, we spatially extrapolated model predictions and evaluated the predictive accuracy using two additional radio-tracking datasets from distant populations as well as sighting data from the whole area. Model evaluation, using independent datasets, reduces the risk of spurious habitat inferences, but they are seldom available (Mladenoff et al., 1999; Pearce and Ferrier, 2000). Finally, we give examples on how to use our model predictions in wildcat conservation.

\section{Methods}

\subsection{Study area}

We radio-tracked wildcats and developed the initial habitat model in an area encompassing $150 \mathrm{~km}^{2}$ in south-western Germany $\left(50^{\circ} 3^{\circ} \mathrm{N}, 6^{\circ} 39^{\circ} \mathrm{E}\right)$ in the western part of RhinelandPalatinate in the low mountain range Eifel (Fig. 1, "Southern Eifel"). It is a rural area with a population density of about 70 inhabitants per $\mathrm{km}^{2}$. Thirty-seven percent of the area is forested. The elevation ranges from $200 \mathrm{~m}$ in the steep forested creek valleys to $450 \mathrm{~m}$ on plateaus dedicated to agriculture. It lies in the Western-European Atlantic climatic region with mild but longsome winters and temperate humid-cool summers. The annual precipitation is $800 \mathrm{~mm}$, the average temperature in January is $0{ }^{\circ} \mathrm{C}$, in July $15{ }^{\circ} \mathrm{C}$. Snow is recorded on an average of 28 days per year.

Model extrapolation and evaluation was performed in a larger area encompassing the whole Federal State RhinelandPalatinate (Fig. 1; 19,850 $\mathrm{km}^{2}$ ). Average population density is $200 \mathrm{inh} / \mathrm{km}^{2}$. The State is characterised by low mountain ranges and large forests covering $42 \%$ of the surface. The dominant native trees, red beech (Fagus sylvatica) and oak (Quercus spec.), were commonly replaced by spruce (Picea abies), pine (Pinus sylvestris), and douglas fir (Pseudotsuga menziesii), so that today $44 \%$ of the forests are coniferous (Fischer, 1989; Landesforsten Rheinland-Pfalz, 2006). One evaluation area was situated in the northern part of the low mountain range Eifel with elevations of 450-750 m ("Northern Eifel"). The second evaluation area was the lowland forest "Bienwald" in the southeastern part of Rhineland-Palatinate at the river Rhine (Fig. 1).

\subsection{Wildcat data}

The wildcat habitat model was built using a radio-telemetry database containing 13,000 locations of 12 individuals (6 females, 6 males) captured and monitored between 2001 and 2004. Individuals were radio-tracked for periods between 4 and 30 months each before the signal failed. Locations were performed using triangulation (White and Garrott, 1990). The estimated maximum radio-tracking error was $100 \mathrm{~m}$. Every animal was located once at daytime for at least 10 days per month and monitored intensively (one location every $15 \mathrm{~min}$ ) during at least 20 nights.

For habitat modelling we filtered the initial sample to minimize temporal autocorrelation by selecting only locations separated by at least $6 \mathrm{~h}$. This resulted in a dataset of 2481 locations, ranging between 121 and 477 locations per cat. 


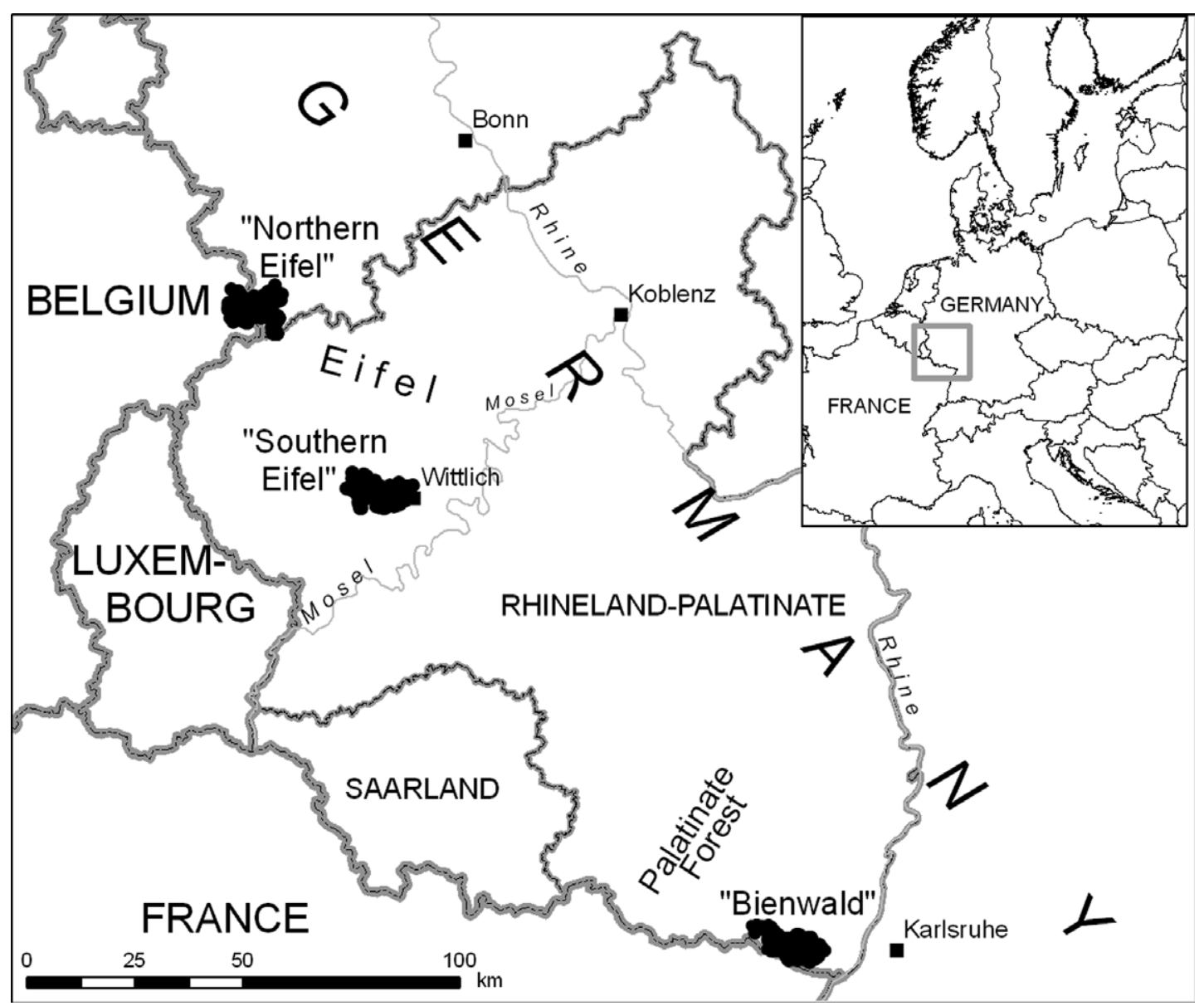

Fig. 1 - Rhineland-Palatinate with location of study areas in black: "Southern Eifel" - training dataset, "Northern Eifel” evaluation dataset 1 and "Bienwald" - evaluation dataset 2.

\subsection{Landscape data}

Land use data were taken from the official German information system for cartography and topography (ATKIS ${ }^{\circledR}$, Landesamt für Vermessung und Geobasisinformation Rheinland-Pfalz, 2002). These maps are vector-based with a $3 \mathrm{~m}$ resolution and contain information on forest (coniferous, deciduous and mixed), coppices, agricultural land, meadows, water, roads and paths, different types of human settlements, single houses and industrial areas. The ATKIS data represent the most detailed land use data available for the whole country. We focused on seven different land use features important for the wildcat including the distance to forest, meadows, forest edge, watercourses, villages, single houses and public roads (Table 1). Distances were measured from each wildcat radio location to the nearest border of these features. Distance to forest was set to 0 within the forest. Forest type was not included because preliminary analyses did not show

Table 1 - Summary of landscape variables measured at wildcat and random locations, Wilcoxon matched pairs test of differences between the mean of individual wildcat locations $(\mathrm{N}=12)$ and individual random locations $(\mathrm{N}=12)$, form of function to include into the models ( $\mathrm{l}$ = linear, $\mathrm{p}-\mathrm{wl}=$ piece-wise linear)

\begin{tabular}{|c|c|c|c|c|c|c|}
\hline \multirow[t]{2}{*}{ Abbreviation } & \multirow[t]{2}{*}{ Variable description } & \multicolumn{2}{|c|}{ Locations (m, means $\pm \mathrm{SE})$} & \multicolumn{2}{|c|}{ Wilcoxon test } & \multirow[t]{2}{*}{ Function } \\
\hline & & Wildcats & Random & $\mathrm{V}$ & $\mathrm{P}$ & \\
\hline D_FOR & Distance to forest. Locations within forest $=0$ & $8 \pm 0.02$ & $54 \pm 0.08$ & 78 & $<0.001^{*}$ & 1 \\
\hline D_MEA & Distance to nearest meadow. Location on meadow $=0$ & $169 \pm 0.12$ & $161 \pm 0.13$ & 33 & 0.677 & 1 \\
\hline D_EDG & Distance to forest edge & $147 \pm 0.11$ & $167 \pm 0.11$ & 63 & 0.063 & 1 \\
\hline D_WAT & Distance to nearest watercourse (creek, stream, river) & $204 \pm 0.14$ & $260 \pm 0.14$ & 71 & $0.009^{*}$ & 1 \\
\hline D_VIL & Distance to nearest settlement or village & $1171 \pm 0.35$ & $937 \pm 0.40$ & 4 & $0.003^{*}$ & $\mathrm{p}-\mathrm{wl}<900 \mathrm{~m}$ \\
\hline D_HOU & Distance to nearest single house & $741 \pm 0.26$ & $683 \pm 0.28$ & 22 & 0.204 & p-wl $<200 \mathrm{~m}$ \\
\hline D_RD & Distance to nearest paved road & $392 \pm 0.18$ & $378 \pm 0.21$ & 33 & 0.677 & $\mathrm{p}-\mathrm{wl}<200 \mathrm{~m}$ \\
\hline
\end{tabular}

* Indicate significant differences at $\mathrm{p}<0.05$. 
any effect on wildcat habitat use (Klar, 2007). Habitat variables were measured using ArcView3.2(ESRI, Inc, Redlands, CA, USA).

\subsection{Statistical analyses}

We analysed habitat use within home ranges using single locations to identify habitats with a higher likelihood of being selected by wildcats. This is referred to as third order selection by Johnson (1980). We designed a use versus availability approach, which has the advantage of not assuming that some areas are never used by individuals in contrast to presence-absence models (Boyce et al., 2002; Pearce and Boyce, 2006). This approach assumes that observed occurrences are a subsample of available sites that inform on animal habitat preferences (Manly et al., 1993). This assumption is reliable since erratic and other movements not directly related to habitat selection are probably rare in resident individuals and, at most, would introduce a random error in the occurrence subsample.

To avoid overrepresentation of some particular individuals in the radio tracking sample, we randomly chose an equal amount of locations per cat $(n=121)$. As a sample of availability, we distributed the same amount of random locations ( $n=121$ ) within an $800 \mathrm{~m}$ buffer around each individual home range, defined by the $100 \%$ minimum convex polygon (MCP). The 800-m buffer represents the mean distance of wildcat displacement within $24 \mathrm{~h}$. Home ranges, buffer areas and random locations were produced using ArcView3.2 (ESRI) and the extension Animal Movement 2.04 (Hooge and Eichenlaub, 1997). Human settlements were excluded from the home range area before distributing random points.

We preliminarily explored the differences in mean values between habitat variables in wildcat locations and the ran- dom availability sample using Wilcoxon matched pairs tests. In addition, a correlation matrix was built for all variables using Spearman's rank coefficient.

Habitat selection analyses were based on information-theoretic methods that include a priori specification and mathematical formulation of different hypotheses and their final confrontation rewarding for parsimony (see Johnson and Omland, 2004; Rushton et al., 2004 for reviews; Greaves et al., 2006). First, we designed a set of 13 candidate models for wildcat occurrence guided by three general hypotheses: (1) Wildcats require cover and shelter found mainly in the forests to hide from humans and bigger predators (Piechocki, 1990). (2) Habitat use is strongly linked to landscape characteristics favouring rodent abundance, the main prey of wildcats, like forest edges, watercourses and meadows (e.g. Doyle, 1990; Gomez and Anthony, 1998; Osbourne et al., 2005). (3) Wildcats avoid the proximity of human settlements, because of noise, light, and the presence of people and dogs (Table 2). Variables with a strong correlation (Spearman's rank correlation >0.6) were not included in the same model (Fielding and Haworth, 1995).

In order to avoid linearity assumptions, we preliminarily explored the shape of the response for each landscape variable before fitting them into the final equations (Austin, 2002). With this aim, we built Generalised Additive Models (GAMs) (Hastie and Tibshirani, 1990) using wildcat locations/random points as response variable and fitting smoothing splines with 3 degrees of freedom to model every habitat effect. The smoothed variables were then turned into suitable parametric terms guided by visual inspection of the partial residual plots (Crawley, 2005). The postulated candidate models were then fit to the radio-tracking dataset using generalized linear mixed models (GLMM) with logistic link, binomial error structure and linear and non-linear responses to fixed effects in accordance with the GAM results. As the cats actually monitored represent a

Table 2 - Summary of models for predicting wildcat habitat use in four groups corresponding to different hypotheses of landscape factors potentially affecting wildcat habitat use

\begin{tabular}{llc} 
Candidate models GLMM & AIC & Weighted AIC \\
\hline Null Model & \\
Oa intercept only & 3801.1 & 0.00 \\
Forests (shelter) & \\
1a D_FOR & 3513.8 \\
Human disturbance & \\
2a D_FOR + D_VIL & 3497.2 & 0.00 \\
2b D_FOR + D_RD & 3501.6 \\
2c D_FOR + D_VIL + D_HOU + D_RD & 3395.0 \\
Food availability & \\
3a D_FOR + D_EDG & 3513.3 \\
3b D_FOR + D_MEA & 3504.3 \\
3c D_FOR + D_WAT & 3480.9 \\
3d D_FOR + D_WAT + D_MEA & 3481.4 \\
3e D_FOR + D_WAT + D_EDG & 3482.5 \\
Human disturbance and food availability (global) & \\
4a D_FOR + D_WAT + D_VIL & 3339.7 \\
4b D_FOR + D_WAT + D_VIL + D_HOU + D_MEA & 3324.5 \\
4c D_FOR + D_WAT + D_VIL + D_HOU + D_MEA + D_RD & 3321.4 \\
4d D_FOR + D_WAT + D_VIL + D_HOU + D_EDG + D_RD & 3333.7 \\
\hline GLME & 0.00 \\
\hline
\end{tabular}

GLMM: generalised linear mixed models; AIC: Akaike’s information criterion; Abbreviated landscape variables see Table 1. 
random sample of all trappable wildcats potentially present in the study area, we controlled for the effect of the individual including it as a random term.

Fitted models were compared and hierarchically ordered using Akaikes Information Criterion (AIC), a statistic method that rewards parsimony by penalizing the maximum likelihood for the number of model parameters (Akaike, 1973; Richards, 2005). Finally, we evaluated model selection uncertainty weighting all AIC values using a randomisation method. For this we included the full dataset of cat locations (2481 locations filtered for temporal independence and 2481 random points) and randomly chose 100 locations per cat and an equal amount of random points within wildcat home ranges. Then we fitted all 13 models, calculated the AIC and recorded the model with the lowest value. This routine was iterated 10,000 times, and the probability of model selection was estimated counting the number of randomisations in which each model was scored as best.

All statistical analyses were performed using the R statistical software V. 2.3.0 (R Development Core Team 2006, Vienna, Austria), GAM and GLMM were fitted using the gam and lme4 packages, respectively.

\subsection{Model evaluation}

We first evaluated the accuracy of habitat predictions, using an independent random sample of wildcat locations from the "Southern Eifel" dataset not used for model fitting. In addition, we evaluated predictions outside the calibration range using radio-tracking data from two areas situated 50 and $150 \mathrm{~km}$ apart from the calibration area (Fig. 1). The "Northern Eifel" dataset consisted of 7700 radio locations from 7 males and 3 females, monitored from 2002 to 2004 in an area of $150 \mathrm{~km}^{2}$. The "Bienwald" dataset consisted of 800 radio locations of 5 males and 5 females, monitored in 2005 and 2006 in an area of $130 \mathrm{~km}^{2}$.

We assessed model predictive accuracy by comparing predictions to the observed number of wildcat locations in the evaluation datasets following the method suggested by Boyce et al. (2002) (e.g. Nielsen et al., 2004). This method relates model predictions to the probability of habitat use from presence-only data. This is an advantage over more traditional methods such as ROC and Kappa, because a true binary dataset is not required (Pearce and Boyce, 2006). First, predictions from the selected model were translated into a grid map with $25 \cdot 25 \mathrm{~m}$ grids covering Rhineland-Palatinate. Then we ranked probability values into eight classes of equal area amounts. The proportion of wildcat locations within each probability class was calculated and divided by the proportion of the available area. Last, the area-adjusted use frequencies were correlated with the probability ranks using Spearman rank correlation. High correlation scores indicate that areas resulting in high predicted probability of use are indeed used more often in relation to availability, therefore indicating high model accuracy.

\subsection{Habitat mapping}

We aim at providing information in detail regarding habitat selection within home ranges, facilitating the mapping of suitable wildcat habitats at this detailed level. However, we also wanted to exclude those habitat patches potentially suitable for wildcats but too small or too scattered to constitute part of home ranges. Therefore we formulated a set of rules for predicted habitat patches that may constitute home ranges as defined by the $100 \% \mathrm{MCP}$ of all 14 females in the three study areas (Fig. 3). First, we defined a circular area of 700 ha - i.e. $1500 \mathrm{~m}$ radius - representing the average female home range size. Each cell was assigned as a potential home range centre if all the following rules were followed: (1) Human settlements are not present within the 700 ha circular area; (2) suitable habitat (probability $>0.45$ ) constitutes at least 185 ha of the area and (3) optimal habitat $(p>0.65)$ at least 94 ha. These thresholds correspond to the values calculated from the female home range with the smallest amount of suitable habitat. Therefore, we take as much area as possible which still fulfils the characteristics of the least optimal home range recorded. The sensitivity of the rules was evaluated changing values of suitable and optimal habitat between the minimum and the average value within female home ranges and amount of settlements between minimum and maximum (see Appendix, Tables A.1, A.2). The rules were implemented using a moving window routine in ArcView3.2. Later the suitable home range centre cells were buffered with the surrounding connected forest patch plus $300 \mathrm{~m}$. This was done to give the predicted area a more natural shape, since wildcats shaped their home ranges around forest patches and used only areas close to forests for hunting. This area was then assigned as the total area of potential home ranges within the map area. Within this area habitat quality can be addressed due to the fine-scale model predictions.

A dataset of 2306 wildcat observations and 333 casualties from a systematic questionnaire survey for Rhineland-Palatinate with an accuracy of $1 \mathrm{~km}$ (Knapp et al., 2000) was used to compare our home range predictions with wildcat distribution data. We recognise that observational data may be biased for example due to potential habitat-dependent probability of observing wildcats and the sporadic confusion with domestic cats. Still, this source of information provides an unique opportunity to confront our fine-scale habitat predictions with coarse-grained distributional data frequently used in conservation.

\section{Results}

The exploratory univariate analyses showed that distances from wildcat locations to forests and watercourses were significantly lower than random, whereas distances to villages were significantly higher (Table 2). Other differences were not significant. A strong correlation was only observed between distance to forest edge and to meadows $(r=0.68$, $\mathrm{p}<0.001$ ).

The visual inspection of GAMs indicated a linear relationship between wildcat occurrence and all predictors, except for the distance to villages, houses and roads, which were modelled as piece-wise linear effects. The best threshold according to the lowest residual deviance (Crawley, 2005) was $900 \mathrm{~m}$ for villages and $200 \mathrm{~m}$ for single houses and roads, indicating that wildcat habitat use was affected by human 
disturbance only up to moderate distances smaller than the average length of home ranges.

\subsection{Model selection}

The global models including human disturbance and surrogates of food availability showed the highest parsimony ranks according to AIC scores. The selected model (4c, Table 3) included as predictors the distance to forest, water, villages, single houses, meadows and roads. Uncertainty analysis revealed a selection probability of 0.58 for this model. The second best model 4d, which included forest edge and not meadows, showed a probability of 0.36 , whereas other alternative models were selected with a much lower probability (Table 3). Parameter estimates for the two best models are shown in Table 3.

\subsection{Model evaluation and habitat predictions}

The correlation between model predictions and area-adjusted frequencies was high and significant for the training dataset $\left(r_{\mathrm{s}}=0.99, \mathrm{p}<0.001\right)$ and the three evaluation datasets ("Bienwald": $r_{\mathrm{s}}=0.91, \mathrm{P}=0.004$; “Northern Eifel": $\mathrm{r}_{\mathrm{s}}=1, \mathrm{P}<0.001$; "Southern Eifel": $r_{s}=0.97, P<0.001$; Fig. 2). This indicates that the selected model was highly reliable in predicting wildcat habitat use throughout a broad spatial extent (Fig. 1). According to model predictions, the Bienwald area (Fig. 3(2)) contains mainly one large habitat patch - the Bienwald - surrounded by mostly unsuitable area with only a few small habitat patches embedded. Six out of nine radio-tracked wildcats used the largest habitat patch exclusively, selecting the parts with the highest suitability close to forest meadows and watercourses, whilst the other three also used small patches. In the Northern Eifel area (Fig. 3(3)) all females used a large habitat patch and only the males additionally used smaller surrounding patches.

Mapping minimum requirements for female home ranges showed that $46 \%\left(9124 \mathrm{~km}^{2}\right.$ ) of Rhineland-Palatinate was suitable for wildcats (Fig. 4). This represents a capacity of up to 1600 females. $90 \%$ of the wildcat observations (Knapp et al., 2000 ) and $78 \%$ of road kills were located within the suitable area for female home ranges. Additionally, large areas without observed wildcat presence in the north were predicted as suitable for the wildcat (Fig. 4). Sensitivity analyses showed that varying the home range requirement rules resulted in a maximum discrepancy of approximately $1800 \mathrm{~km}^{2}$ in the amount of suitable habitat (Appendix, Table A.2).

\section{Discussion}

\subsection{Wildcat habitat inferences}

Three main land use features influenced wildcat habitat use in our Central European study areas: proximity to close vegetation in forests, proximity to forest ecotones with water and meadows, and the distance to human settlements and roads. The most influential was proximity to forests, with $75 \%$ male and $91 \%$ female radio locations in forested habitats. Wildcat dependence on forests has been previously discussed in larger-scale studies (e.g. Lozano et al., 2003) and is probably related to wildcat requirements of cover for sheltering (Parent, 1975; Stahl, 1986; Piechocki, 1990; Wittmer, 2001). The intense land-cover transformation of Central European landscapes has left forests as almost the only sheltering vegetation. Unfortunately we are not able to address the question of a minimum size for suitable forest patches, because within our study area only one more or less connected forest patch was present.

However, forest presence alone does not fully explain wildcat habitat use. A close distance to edges between forest and watercourses or meadows was also important in our study. This is probably related to the availability of prey. During activity hours we often observed wildcats hunting rodents on meadows close to the forest edge and near creeks, while the daytime resting often took place within dense structures in the forest. Riparian areas within forest as well as edge habitats often provide a higher diversity and abundance of small prey mammals than interior forest (e.g. Doyle, 1990; Gomez and Anthony, 1998; Osbourne et al., 2005). But also in agricultural areas, small mammals can reach higher densities near streams (Chapman and Ribic, 2002; Sullivan and Sullivan, 2006). Wet areas represent good habitat for water voles (Arvicola terrestris), which are an especially profitable prey in terms of their comparatively high body mass (Niethammer and Krapp, 1982; Liberek, 1999; Dieterlen, 2005). Riparian areas may also provide additional shelter in terms of riparian vegetation within non-forested areas. The importance of eco-

Table 3 - Estimated coefficients and standard error for the variables of the two best models 4c and 4d

\begin{tabular}{lcc} 
Variables & Estimates model 4c & Estimates model 4d \\
\hline (Intercept) & $1.1479 \pm 0.0872^{* * * * *}$ & $1.0569 \pm 0.0845^{* * * *}$ \\
D_FOR & $-0.0125 \pm 0.0012^{* * *}$ & $-0.0115 \pm 0.0012^{* * *}$ \\
D_MEA & $-0.0011 \pm 0.0003^{* * *}$ & $-0.0006 \pm 0.0003^{*}$ \\
D_EDG & & $-0.0016 \pm 0.0002^{* * *}$ \\
D_WAT & $-0.0014 \pm 0.0002^{* * * *}$ & $0.0024 \pm 0.0002^{* * *}$ \\
I((D_VIL-900) - (D_VIL < 900)) & $0.0024 \pm 0.0002^{* * * *}$ & $0.0041 \pm 0.0019^{*}$ \\
I((D_HOU-200) - (D_HOU < 200)) & $0.0044 \pm 0.0019^{*}$ & $0.0015 \pm 0.0008$ \\
I((D_RD-200) - (D_RD < 200)) & $0.0019 \pm 0.0008^{*}$ & \\
\hline
\end{tabular}

For all places in more than $900 \mathrm{~m}$ distance from villages and $200 \mathrm{~m}$ from houses or roads, respectively, parameter estimates for these parameters were defined to be zero. Abbreviations for landscape variables see Table 1.

* Significant at 0.05 .

*** Significant at 0.001 . 


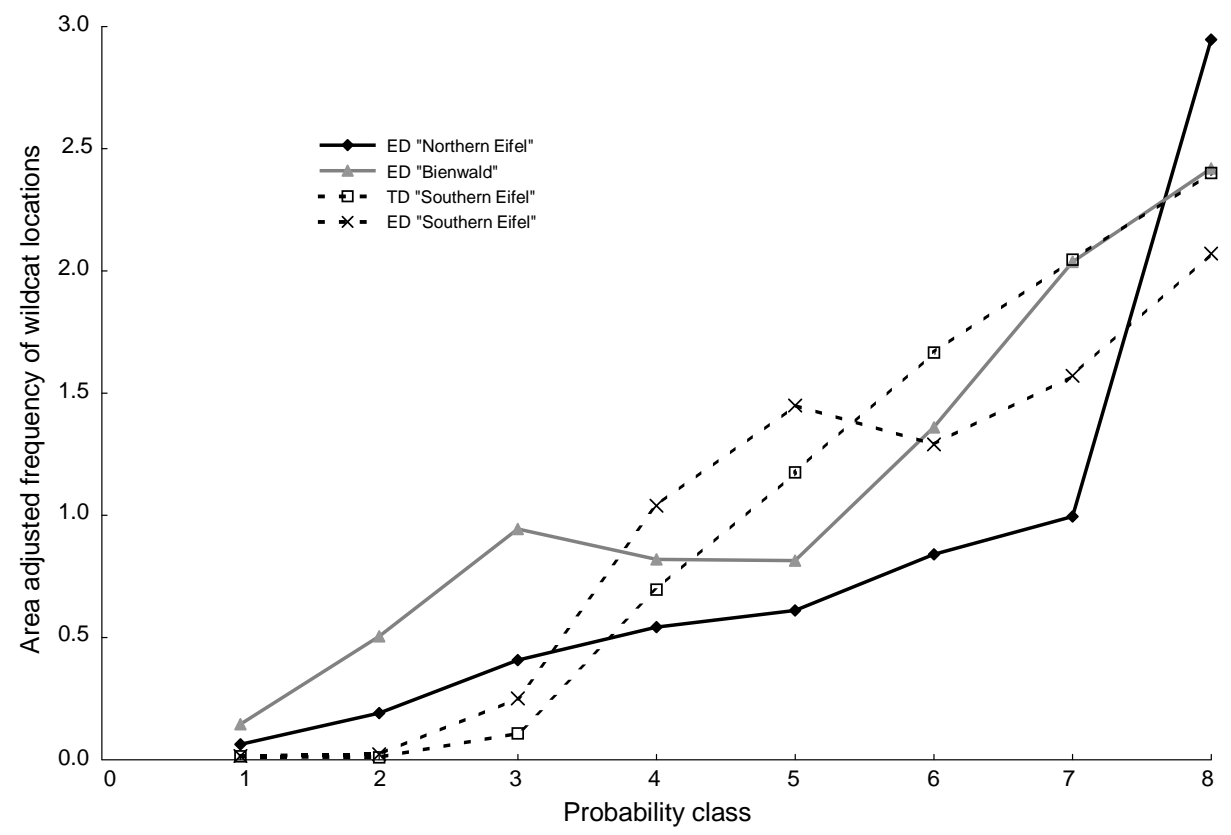

Fig. 2 - Area-adjusted frequency of wildcat locations by probability classes of the best model 4c. Frequency values for the two evaluation datasets (ED) "Northern Eifel" and "Bienwald" are shown, as well as for the training dataset (TD) "Southern Eifel" and a random evaluation dataset (ED) from the "Southern Eifel" database. Spearman-rank correlations for frequency values by probability classes for each dataset $(r>0.9, p<0.005)$ indicate that the model predicts wildcat locations well throughout Rhineland-Palatinate.

tones between sheltering and open vegetation for wildcats has also been inferred from snow tracking data by Okarma et al. (2002) and radio-tracking by Wittmer (2001) and documented in another European felid, the Iberian lynx (Fernández et al., 2003).

The third important habitat feature was the distance to human-related land use types like settlements, single houses and roads. A critical distance from these features affected wildcat spatial behaviour: The probability of wildcat habitat use decreases at distances lower than $900 \mathrm{~m}$ from villages and $200 \mathrm{~m}$ from roads and single houses, respectively. Interestingly, a similar avoidance of a 200-m buffer around houses and roads was also found for the Eurasian lynx (Sunde et al., 1998). This could be due to the combination of noise, light, disturbance by human walkers and the presence of dogs and feral cats. Our personal observations showed a quite strict separation of wild- and feral-cats. This could be one reason for the low hybridisation rate of wild- and domestic-cats in Central Europe (Pierpaoli et al., 2003). The fact that critical distances from human-related structures are, of course, highly dependent on the habitat itself and on relief structure, is shown by our personal observations of wildcats in the "Northern Eifel" study area: they used the area behind an old railroad embankment very close to a village and the bank of a watercourse to even cross through a village.

\subsection{Modelling approach}

Our habitat modelling approach is a use versus availability design: All resource units within the sampling domain are assumed to be available, but some locations are likely to be used more frequently than others. Hence, the output is a relative probability of use (Pearce and Boyce, 2006). One advantage over the more traditional presence-absence approach is that we do not have an asymmetry of errors, which occurs when species are cryptic and absences are not as reliable as presences (Boyce et al., 2002; Johnson et al., 2006). The within home range approach or third order selection (Johnson, 1980) allowed us to detect habitat preferences in very fine detail. Therefore, it could be used to understand basic specieshabitat relationships and also be applied in environmental impact assessments (Seoane et al., 2006). Nonetheless, these predictions are only valid within areas of wildcat occurrence. To predict wildcat habitat over a larger area and for areas without present wildcat occurrence, we superimposed rules derived from home range attributes at a higher level of selection, similar to rule-based modelling approaches (e.g. Schadt et al., 2002a; Fernández et al., 2006b). Predictions from the combination of the fine-scale habitat model and home range rules matched well with wildcat observations throughout Rhineland-Palatinate. Unfortunately, wildcat absences could not be evaluated because the severe reduction in their range due to past hunting and trapping weakens the reliability of habitat inferences (Piechocki, 1990). To use wildcat observations for model evaluation might be problematic in several respects: (1) confusion with feral cats; (2) easier observation in open habitats; (3) biased by the observers expectations in terms of habitat preferences. Aware of these restrictions we used these data only for a rough comparison between our home range predictions and the known distribution of wildcats in Rhineland-Palatinate, failing better information on area-wide wildcat distribution.

One common problem in predictive habitat modelling is transferability to other geographical regions, because 

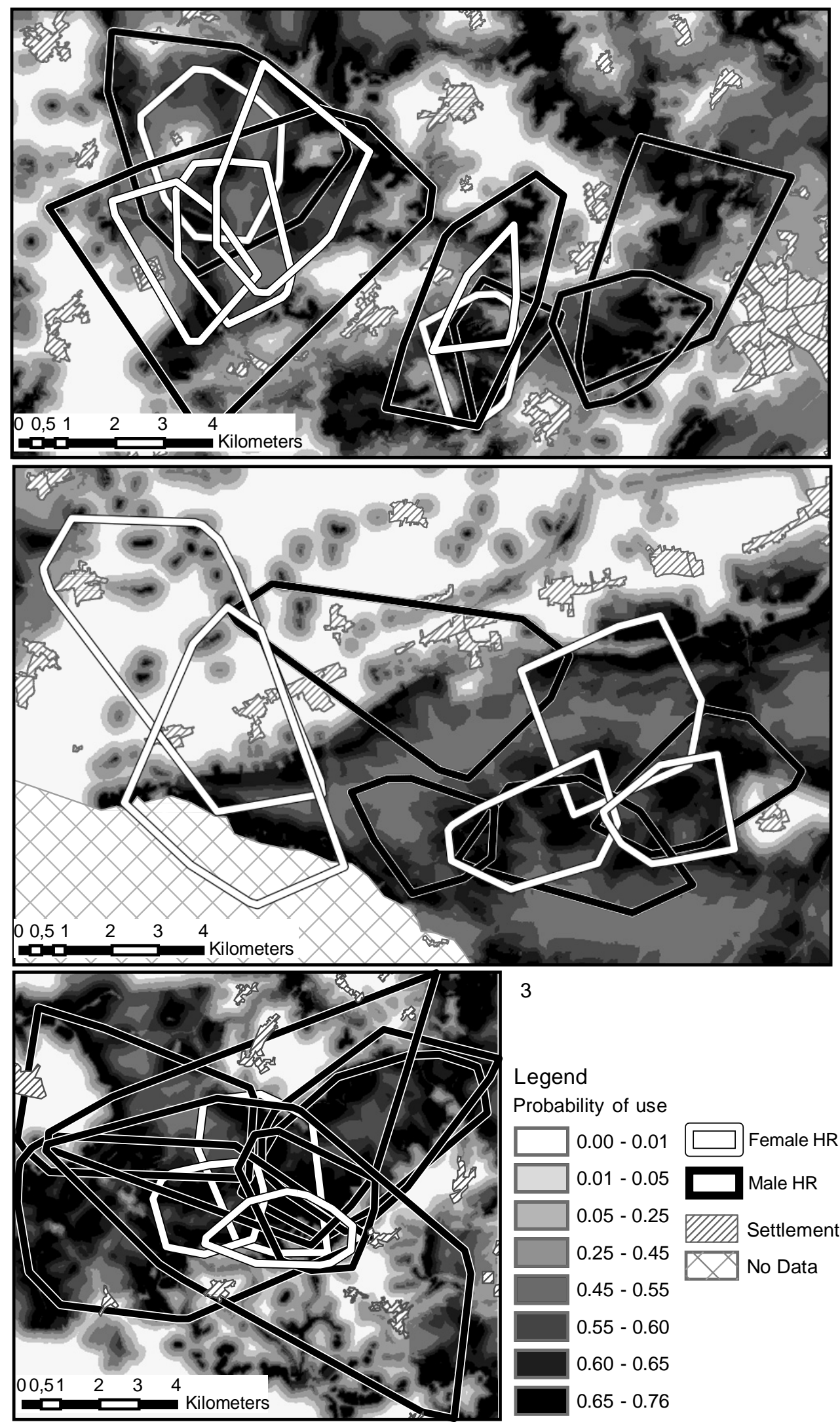

3

Legend

Probability of use

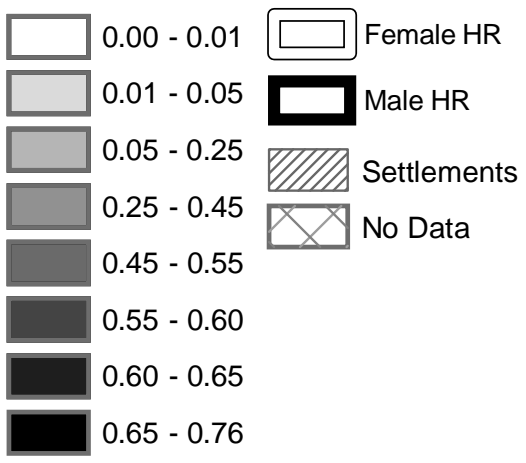

Fig. 3 - Predictive habitat map with Minimum Convex Polygons for all observed wildcats in 3 study areas. Values for the habitat predictions are presented in probability classes as used for the evaluation. (1) Training area "Southern Eifel"; (2) Evaluation area "Bienwald"; (3) Evaluation area "Northern Eifel". 


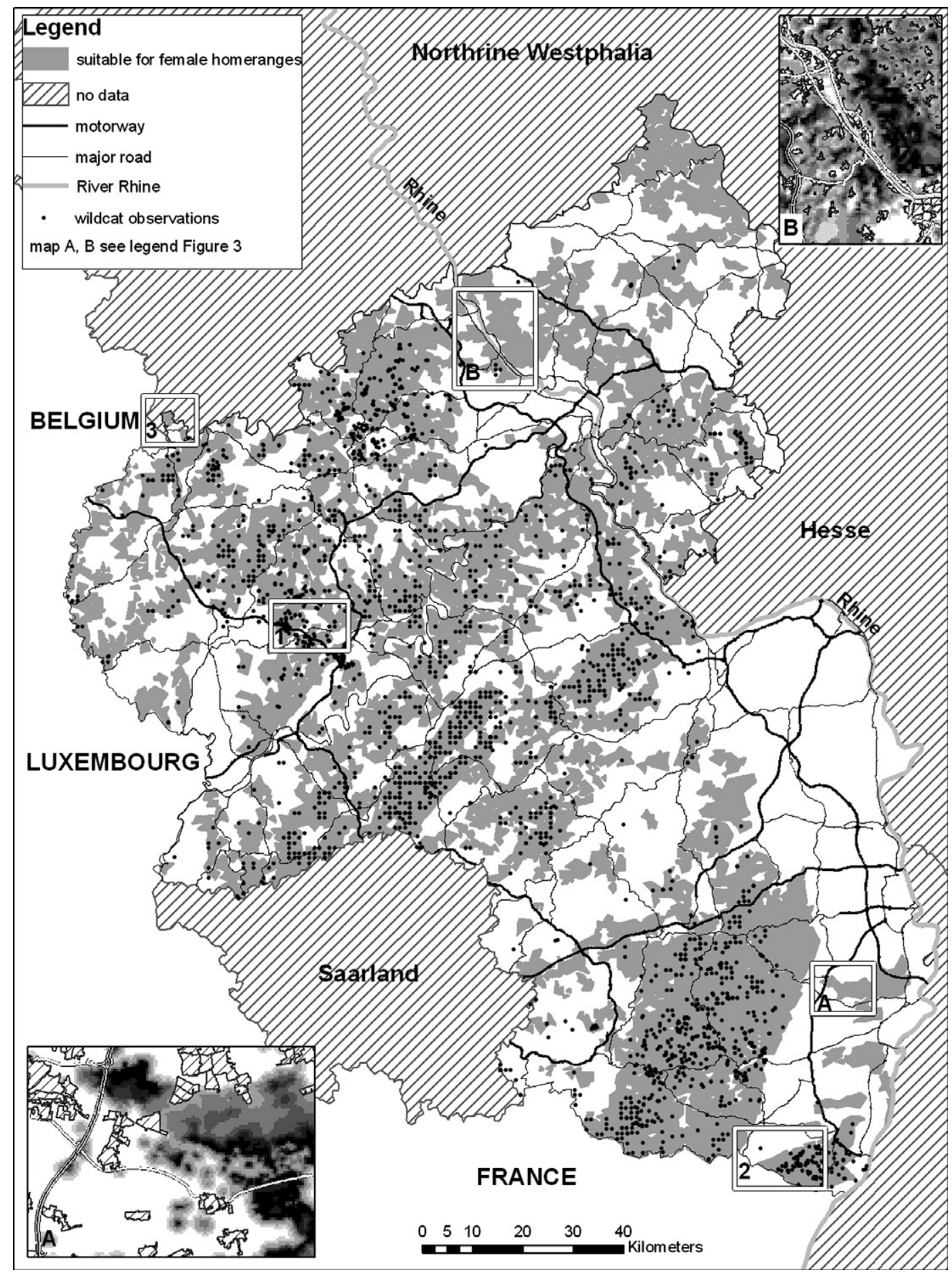

Fig. 4 - Suitable habitat for female home ranges and wildcat observations within the federal state Rhineland-Palatinate. (1), (2), (3): The three study areas shown in Fig. 3. (A and B) unoccupied but suitable habitat patches: detailed predictive habitat map and human infrastructure (legend see Fig. 3).

species-habitat relationships may vary significantly (Fielding and Haworth, 1995; Guisan and Zimmermann, 2000; Osborne and Suárez-Seoane, 2002). To address this problem, we evaluated our model with two independently collected datasets from outside its calibration range. The training data set, as well as the evaluation dataset "Northern Eifel", were collected in a low mountain range but at different elevations, 200$450 \mathrm{~m}$ and $450-750 \mathrm{~m}$, respectively. Here, the non-forested areas differed in the amount of meadows which were more abundant in the evaluation dataset. The "Bienwald" dataset 
was collected in a lowland forest, with more watercourses and less fragmentation than the other regions. Despite these landscape differences, the model performed well in both evaluation regions. Consequently, we believe that our model can greatly help to predict wildcat habitats in other regions than the study area, although specific evaluation in new extrapolation areas is recommended where possible. Moreover, the landscape variables can easily be obtained from available digital information in many other regions, which allows evaluating our predictions to a broader spatial extent.

\subsection{Conservation and management implications}

As shown in Fig. 4, about half of the study area was identified as suitable for wildcat home ranges. The approach of developing rules of minimal habitat requirements from observed home ranges is conservative, so that we might have overlooked some areas which could also be suitable for wildcats. Due to the historical decline in wildcat populations, not all predicted habitats are populated to date. For example, within the small habitat patches in the southern Rhine valley (Fig. 4A) and northeast of the river Rhine (Fig. 4B) no wildcats could be detected after 1970 (Röben, 1974; Vogt and Grünwald, 1990). Despite the slow expansion of the wildcat population after its total protection in the 1930s and the consistent suitability of the patches, wildcats did not succeed in repopulating the area. This might be due to the large distance to the nearest populated habitat patch together with barriers in terms of human infrastructure, which are abundant in the Rhine valley. The small size of the patches could also play a role.

The wildcat as a species of the Annex IV in the European Habitats Directive should be maintained in a favourable conservation status. Therefore, information on potential population size within a patch, connectivity of patches and on habitat quality is essential. With the predictive habitat map, we were able to show that Rhineland-Palatinate contains large areas of connected habitat in the central and north-western part (Eifel and Hunsrück) which is partly connected to the North Rhine-Westphalian, Belgian and Luxembourg populations. The large area predicted as suitable habitat and the connectivity with other populations seem to provide good conditions for the viability of wildcats in the centre of RLP. However, the high density of roads and motorways may also pose a threat to wildcats throughout the whole area. A rough estimation shows that this area is large enough for about 1500 wildcats. For a more exact population size estimation data on forest structure and food abundance as well as demographic parameters would be needed. In the south the Palatinate Forest and surroundings form an isolated habitat patch which is still big enough to host about 650 wildcats and is connected to the French population in the Northern Vosges. Our model helped also to identify the small isolated habitat patch Bienwald (Fig. 4B) which only provides space for about 45 cats. This population most likely depends on the connection to the larger Palatinate Forest population for a long term survival. The fine-scale habitat map (Fig. 3(2)) can here be used to find existing small areas of suitable habitat which could be enlarged and connected as a conservation measure to promote corridors between both populations (Kautz et al., 2006).

The large unoccupied but suitable area in the northeast could become a potential reintroduction site for wildcats to promote the expansion of the population towards the east and the reconnection with other wildcat populations in Germany. In this case additional connections to the existing population over the river Rhine with its large amount of human infrastructure should be provided. Again the fine-scale habitat map can help to find good locations for the connection (Fig. 4B).

Our model and fine-scale habitat map was used to simulate different landscape management scenarios for a planned golf course and to give advice on where to place it for the least impact on the wildcat in terms of habitat loss (Herrmann et al., 2006). Compensation measures could be recommended according to the amount of lost habitat. Such use of the maps and the model is reliable within the study area of RhinelandPalatinate, similar regions in terms of landscape composition or other areas after an additional evaluation of the model with regional wildcat data.

\section{Acknowledgements}

NK is grateful for the support to the Dr. Joachim and Hanna Schmidt Stiftung für Umwelt und Verkehr. NF was supported by a Marie Curie Host Fellowship provided by the European Commission (HPMD-CT-2001-00109). We thank J. Jepsen, F. Palomares, H. Bauer and two reviewers for their helpful comments in earlier stages of this work. K. Birlenbach, C. Steffen, S. Schröder, M. Hötzel, C. Thiel, P. Gräser, S. Fehling and numerous students helped with the field work.

\section{Appendix}

See Tables A.1 and A.2.

Table A.1 - 100\% Minimum convex polygon (MCP) area, amount of settlements, optimal habitat $(\mathrm{p}>0.65)$ and suitable habitat $(\mathrm{p}>0.45)$ in ha within each of the 14 radio-tracked female wildcats home ranges

SE1 SE2 SE3 SE4 SE5 SE6 $\quad$ BW1 BW2 BW3 BW4 BW5 NE1 NE2 NE3 Min Max Ave Median

$\begin{array}{lcccccccccccccccccc}\text { Settlements } & 0 & 0 & 0 & 0 & 5 & 13 & 0 & 0 & 0 & 45 & 63 & 0 & 0 & 0 & 0 & 63 & 9 & 0 \\ \mathrm{p}>0.65 & 94 & 131 & 140 & 55 & 48 & 73 & 193 & 273 & 236 & 156 & 231 & 511 & 258 & 256 & 48 & 511 & 190 & 175 \\ \mathrm{p}>0.45 & 185 & 645 & 320 & 439 & 459 & 329 & 628 & 1203 & 632 & 576 & 559 & 938 & 382 & 518 & 185 & 1203 & 558 & 539 \\ 100 \% \text { MCP } & 243 & 891 & 381 & 598 & 733 & 527 & 645 & 1514 & 748 & 2658 & 1975 & 1020 & 503 & 531 & 243 & 2658 & 926 & 689\end{array}$

p-Values are taken from the habitat model. SE = Southern Eifel, BW = Bienwald, NE = Northern Eifel. The cat with the lowest amount of suitable habitat is SE1. 


\begin{tabular}{|c|c|c|c|c|c|}
\hline \# & Settlements (ha) & $\begin{array}{c}\text { Suitable } \\
\text { habitat (ha) }\end{array}$ & $\begin{array}{c}\text { Optimal } \\
\text { habitat (ha) }\end{array}$ & $\begin{array}{l}\text { Amount of area } \\
\text { predicted }\left(\mathrm{km}^{2}\right)\end{array}$ & $\begin{array}{l}\text { Sensitivity (\% difference } \\
\text { from } 9124 \mathrm{~km}^{2} \text { ) }\end{array}$ \\
\hline 0 & 0 & 185 & 94 & 9124 & 0 \\
\hline 1 & 0 & 185 & 48 & 9392 & +2.9 \\
\hline 2 & 0 & 185 & 190 & 7888 & -13.5 \\
\hline 3 & 0 & 558 & 48 & 7604 & -16.7 \\
\hline 4 & 0 & 558 & 190 & 7289 & -20.1 \\
\hline 5 & 9 & 185 & 48 & 10,129 & +11.0 \\
\hline 6 & 9 & 185 & 190 & 8003 & -12.3 \\
\hline 7 & 9 & 558 & 48 & 7604 & -16.7 \\
\hline 8 & 9 & 558 & 190 & 7289 & -20.1 \\
\hline 9 & 63 & 185 & 48 & 10,904 & +19.5 \\
\hline 10 & 63 & 185 & 190 & 8009 & -12.2 \\
\hline 11 & 63 & 558 & 48 & 7605 & -16.6 \\
\hline 12 & 63 & 558 & 190 & 7289 & -20.1 \\
\hline
\end{tabular}

The maximum amount of settlements was varied between the minimum and maximum amount within female home ranges (see Table A.1). The minimum amounts of suitable habitat and optimal habitat were varied between the minimum and the average amounts recorded in female home ranges. Scenario \#0 corresponds to parameter values recorded from the cat with the lowest amount of suitable habitat within the home range (Table A.1, SE1).

\section{R E F E R E N C E S}

Akaike, H., 1973. Information theory as an extension of the maximum likelihood principle. In: Petrov, B.N., Csaki, F. (Eds.), Second International Symposium on Information Theory. Akademiai Kiado, Budapest, Hungary, pp. 267-281.

Austin, M.P., 2002. Spatial prediction of species distribution: an interface between ecological theory and statistical modelling. Ecological Modelling 157, 101-118.

Biró, Z., Lanszki, J., Szemethy, L., Heltai, M., Randi, E., 2005. Feeding habits of feral domestic cats (Felis catus), wild cats (Felis silvestris) and their hybrids: trophic niche overlap among cat groups in Hungary. Journal of Zoology 266, 187-196.

Boyce, M.S., Vernier, P.R., Nielsen, S.E., Schmiegelow, F.K.A., 2002. Evaluating resource selection functions. Ecological Modelling 157, 281-300.

Chapman, E.W., Ribic, C.A., 2002. The impact of buffer strips and stream-side grazing on small mammals in southwestern Wisconsin. Agriculture, Ecosystems and Environment 88, 49-59.

Crawley, M.J., 2005. Statistics: An Introduction using R. John Wiley \& Sons Ltd., Chichester.

Dieterlen, F., 2005. Schermaus (Ostschermaus, Große Wühlmaus) Arvicola terrestris (Linnaeus, 1758). In: Braun, M., Dieterlen, F. (Eds.), Die Säugetiere Baden-Württembergs, Eugen Ulmer, Stuttgart, pp. 328-341.

Doyle, A.T., 1990. Use of riparian and upland habitats by small mammals. Journal of Mammalogy 71, 14-23.

Fernández, N., Delibes, M., Palomares, F., Mladenoff, D.J., 2003. Identifying breeding habitat for the Iberian lynx: Inferences from a fine-scale spatial analysis. Ecological Applications 13, 1310-1324.

Fernández, N., Delibes, M., Palomares, F., 2006a. Landscape evaluation in conservation: Molecular sampling and habitat modelling for the Iberian lynx. Ecological Applications 16, 1037-1049.

Fernández, N., Kramer-Schadt, S., Thulke, H., 2006b. Viability and risk assessment in species restoration: planning reintroductions for the wild boar, a potential disease reservoir. Ecology and Society 11, 6.

Fielding, A.H., Haworth, P.F., 1995. Testing the Generality of BirdHabitat Models. Conservation Biology 9, 1466-1481.

Fischer, H., 1989. Rheinland-Pfalz und Saarland. Eine geographische Landeskunde. fourth ed. Wissenschaftliche Buchgesellschaft, Darmstadt.
Gomez, D.M., Anthony, R.G., 1998. Small mammal abundance in riparian and upland areas of five seral stages in Western Oregon. Northwest Science 72, 293-302.

Greaves, R.K., Sanderson, R.A., Rushton, S.P., 2006. Predicting species occurrence using information-theoretic approaches and significance testing: An example of dormouse distribution in Cumbria, UK. Biological Conservation 130, 239-250.

Guisan, A., Zimmermann, N.E., 2000. Predictive habitat distribution models in ecology. Ecological Modelling 135, 147-186.

Hastie, T.J., Tibshirani, R.J., 1990. Generalized Additive Models. Chapman \& Hall, London.

Herrmann, M., Knapp, J., Klar, N., 2006. Erheblichkeitsabschätzung Wildkatze / Luchs im Rahmen des Raumordnungsverfahrens Erlebnisregion Nürburgring, pp. 35. Parlow: OEKO-LOG.COM.

Hooge, P.N., Eichenlaub, B., 1997. Animal Movement extension to ArcView. Alaska Biological Science Center, U.S. Geological Survey, Anchorage.

Johnson, D.H., 1980. The comparison of usage and availability measurements for evaluating resource preference. Ecology 61, 65-71.

Johnson, J.B., Omland, K.S., 2004. Model selection in ecology and evolution. Trends in Ecology \& Evolution 19, 101-108.

Johnson, C.J., Seip, D.R., Boyce, M.S., 2004. A quantitative approach to conservation planning: using resource selection functions to map the distribution of mountain caribou at multiple spatial scales. Journal of Applied Ecology 41, 238-251.

Johnson, C.J., Nielsen, S.E., Merrill, E.H., McDonald, T.L., Boyce, M.S., 2006. Resource Selection Functions Based on UseAvailbility Data: Theoretical Motivation and Evaluation Methods. Journal of Wildlife Management 70, 347-357.

Kautz, R., Kawula, R., Hoctor, T., Comiskey, J., Jansen, D., Jennings, D., Kasbohm, J., Mazzotti, F., McBride, R., Richardson, L., Root, K., 2006. How much is enough? Landscape-scale conservation for the Florida panther. Biological Conservation 130, 118-133.

Klar, N., 2007. Habitatwahl in der Südeifel. In: Hötzel, M., Klar, N., Schröder, S., Stephen, C., Thiel, C. (Eds.), Die Wildkatze in der Eifel - Habitate, Ressourcen, Streifgebiete. Laurenti-Verlag, Bielefeld, pp. 191.

Knapp, J., Herrmann, M., Trinzen, M., 2000. Artenschutzprojekt Wildkatze (Felis silvestris silvestris SCHREBER, 1777) in Rheinland-Pfalz. Oppenheim: Landesamt für Umweltschutz und Gewerbeaufsicht.

Kozená, I., 1990. Contribution to the food of wild cats (Felis silvestris). Folia Zoologica 39, 207-212. 
Kramer-Schadt, S., Revilla, E., Wiegand, T., 2005. Lynx reintroductions in fragmented landscapes of Germany: Projects with a future or misunderstood wildlife conservation? Biological Conservation 125, 169-182.

Landesforsten Rheinland-Pfalz, 2006. Internet representation. Ministerium für Umwelt Forsten und Verbraucherschutz Rheinland-Pfalz. 12.12.2006: www.wald-rlp.de.

Lecis, R., Pierpaoli, M., Biró, Z.S., Szemethy, L., Ragni, B., Vercillo, F., Randi, E., 2006. Bayesian analyses of admixture in wild and domestic cats (Felis silvestris) using linked microsatellite loci. Molecular Ecology 15, 119-131.

Liberek, M., 1999. Eco-é thologie du chat sauvage Felis S. silvestris, Schreber 1777 dans le Jura Vaudois (Suisse). Influence de la couverture neigeuse. Thè se de doctorat, Université de Neuchâtel.

Lozano, J., Virgós, E., Malo, A.F., Huertas, D.L., Casanovas, J.G., 2003. Importance of scrub-pastureland mosaics for wild-living cats occurrence in a Mediterranean area: implications for conservation of the wildcat (Felis silvestris). Biodiversity and Conservation 12, 921-935.

Manly, B.F.J., McDonald, L.L., Thomas, D.L., 1993. Resource Selection by Animals: Statistical Design and Analysis for Field Studies. Chapman \& Hall, London.

Mladenoff, D.J., Sickley, T.A., Wydeven, A.P., 1999. Predicting gray wolf landscape recolonization: Logistic regression models vs. new field data. Ecological Applications 9, 37-44.

Naves, J., Wiegand, T., Revilla, E., Delibes, M., 2003. Endangered species constrained by natural and human factors: The Case of Brown Bears in Northern Spain. Conservation Biology 17, 1276-1289.

Niedzialkowska, M., Jedrzejewski, W., Myslajek, R.W., Nowak, S., Jedrzejewska, B., Schmidt, K., 2006. Environmental correlates of Eurasian lynx occurrence in Poland - Large scale census and GIS mapping. Biological Conservation 133, 63-69.

Nielsen, S.E., Herrero, S., Boyce, M.S., Mace, R.D., Benn, B., Gibeau, M.L., Jevons, S., 2004. Modelling the spatial distribution of human-caused grizzlybear mortalities in the Central Rockies ecosystem of Canada. Biological Conservation 120, 101-113.

Niethammer, J., Krapp, F., 1982. Handbuch der Säugetiere Europas. Akademische Verlagsgesellschaft, Wiesbaden.

Okarma, H., Sniezko, S., Olszanska, A., 2002. The occurrence of wildcat in the Polish Carpathian Mountains. Acta Theriologica 47, 499-504.

Osborne, P.E., Suárez-Seoane, S., 2002. Should data be partitioned spatially before building large-scale distribution models? Ecological Modelling 157, 249-259.

Osbourne, J., Anderson, J., Spurgeon, A., 2005. Effects of habitat on small-mammal diversity and abundance in West Virginia. Wildlife Society Bulletin 33, 814-822.

Parent, G.H., 1975. La migration récente, a caractère invasionnel, du chat sauvage, Felis silvestris Lorraine Belge. Mammalia 39, 251-288.

Pearce, J.L., Boyce, M.S., 2006. Modelling distribution and abundance with presence-only data. Journal of Applied Ecology 43, 405-412.

Pearce, J., Ferrier, S., 2000. Evaluating the predictive performance of habitat models developed using logistic regression. Ecological Modelling 133, 225-245.

Pearce, J.L., Cherry, K., Drielsma, M., Ferrier, S., Whish, G., 2001. Incorporating expert opinion and fine-scale vegetation mapping into statistical models of faunal distribution. Journal of Applied Ecology 38, 412-424.

Peterson, J.T., Dunham, J.A., 2003. Combining inferences from models of capture efficiency, detectability, and suitable habitat to classify landscapes for conservation of threatened bull trout. Conservation Biology 17, 1070-1077.

Piechocki, R., 1990. Die Wildkatze, first ed. A. Ziemsen, Wittenberg Lutherstadt.
Pierpaoli, M., Birò, S., Herrmann, M., Hupe, K., Fernandes, M., Ragni, B., Szemethy, L., Randi, E., 2003. Genetic distinction of wildcat (Felis silvestris) populations in Europe, and hybridization with domestic cats in Hungary. Molecular Ecology 12, 2585-2598.

Pott-Dörfer, B., Raimer, F., 2004. Zur Verbreitung der Wildkatze in Niedersachsen. Informationsdienst Naturschutz Niedersachsen 6, 279-281.

Richards, S.A., 2005. Testing ecological theory using the information-theoretic approach: exmaples and cautionary results. Ecology 86, 2805-2814.

Röben, P., 1974. Die Verbreitung der Wildkatze, Felis silvestris Schreber, 1777, in der Bundesrepublik Deutschland. Säugetierkundliche Mitteilungen 22, 244-250.

Rushton, S.P., Ormerod, S.J., Kerby, G., 2004. New paradigms for modelling species distributions? Journal of Applied Ecology 41, 193-200.

Sawyer, H., Nielson, R.M., Lindzey, F., McDonald, L.L., 2006. Winter habitat selection of mule deer before and during the development of a natural gas field. Journal of Wildlife Management 70, 396-403.

Schadt, S., Knauer, F., Kaczensky, P., Revilla, E., Wiegand, T., Trepl, L., 2002a. Rule-based assessment of suitable habitat and patch connectivity for the Eurasian lynx in Germany. Ecological Applications 12, 1469-1483.

Schadt, S., Revilla, E., Wiegand, T., Knauer, F., Kaczensky, P., Breitenmoser, U., Bufka, L., Cerveny, J., Koubek, P., Huber, T., Stanisa, C., Trepl, L., 2002b. Assessing the suitability of central European landscapes for the reintroduction of Eurasian lynx. Journal of Applied Ecology 39, 189-203.

Seoane, J., Vinuela, J., Diaz-Delgado, R., Bustamante, J., 2003. The effects of land use and climate on red kite distribution in the Iberian peninsula. Biological Conservation 111, 401-414.

Seoane, J., Justribo, J.H., Garcia, F., Retamar, J., Rabadan, C., Atienza, J.C., 2006. Habitat-suitability modelling to assess the effects of land-use changes on Dupont's lark Chersophilus duponti: A case study in the Layna Important Bird Area. Biological Conservation 128, 241-252.

Sládek, S., 1973. Jahreszeitlicheund jahresbedingte Veränderungen der Nahrung der Wildkatze (Felis silvestris, Schreber 1777) in den Westkarpaten. Zoologické Listy 22, 127-144.

Stahl, P., 1986. Le chat forestier d'Europe (Felis silvestris, SCHREBER 1777). Exploitation des ressources et organisation spatiale. Thè se de doctorat, Université de Nancy I.

Stahl, P., Artois, M., 1995. Status and conservation of the wildcat (Felis silvestris) in Europe and around the Mediterranean rim, pp. 76. Strasbourg: Council of Europe.

Stubbe, M., Stubbe, A., 2002. Die Wildkatze kehrt zurück. Wild und Hund 10, 24-25.

Sullivan, T.P., Sullivan, D.S., 2006. Plant and small mammal diversity in orchard versus non-crop habitats. Agriculture, Ecosystems and Environment 116, 235-243.

Sunde, P., Snorre, O.S., Kvam, T., 1998. Tolerance to humans of resting lynxes Lynx lynx in a hunted population. Wildlife Biology 4, 177-183.

Vogt, D., Grünwald, A., 1990. Die Wildkatze. Mainzer

Naturwissenschaftliches Archiv Beiheft 13, 347-356. White, G.C., Garrott, R.A., 1990. Analysis of Wildlife RadioTracking Data. Academic Press, San Diego.

Wittmer, H.U., 2001. Home range size, movements, and habitat utilization of three male European wildcats (Felis silvestris Schreber, 1777) in Saarland and Rheinland-Pfalz (Germany). Mammalian Biology 66, 365-370.

Woolf, A., Nielsen, C.K., Weber, T., Gibbs-Kieninger, T.J., 2002. Statewide modeling of bobcat, Lynx rufus, habitat in Illinois, USA. Biological Conservation 104, 191-198. 